\title{
Constipation in early childhood: patient characteristics, treatment, and longterm follow up
}

\author{
V Loening-Baucke
}

\begin{abstract}
Little is known about chronic constipation in infants, toddlers, and preschool children and longterm outcome after treatment. The symptoms of 174 children $\leq 4$ years of age, who were evaluated for chronic constipation, are reported in this study together with the longterm outcome in $\mathbf{9 0}$ of them. Initial symptoms were infrequent bowel movements in $58 \%$, painful bowel movements in $77 \%$ often with screaming, and severe stool withholding manoeuvres in $97 \%$. The treatment of chronic idiopathic constipation consisted of education, faecal disimpaction, prevention of future impaction, and promotion of regular bowel habits with dietary fibre and milk of magnesia, and finally toilet training of the preschool child. Longterm outcome could be evaluated in 90 patients $(52 \%)$ (mean (SD) $6.9(2.7)$ ) years after initial evaluation. Fifty seven children $(63 \%)$ had recovered, defined as no soiling with $\geq 3$ bowel movements per week, while not receiving treatment. The recovery rate of children $\leq 2$ years of age was significantly higher than in children $>2$ to 4 years of age. Thirty three children (37\%) had not recovered. Constipation recurred as soon as laxatives were discontinued in 31 (94\%) of them. Laxatives were still used by $33 \%$ of the children who had not recovered, $39 \%$ had $<3$ bowel movements per week, $48 \%$ had faecal soiling, $45 \%$ had stool withholding, $27 \%$ complained of abdominal pain, $73 \%$ passed large stools, and $45 \%$ still on occasions clogged the toilet with their large stools. Symptoms of chronic constipation persisted in one third of our patients, 3-12 years after initial evaluation and treatment. Children who had not recovered deserve continued follow up, to reinforce and adjust treatment and to prevent faecal soiling. (Gut 1993; 34: 1400-1404)
\end{abstract}

Constipation represents a common problem in children, accounting for $3 \%$ of visits to the Pediatric Outpatient Clinic at the University of Iowa Hospitals and Clinics as well as to a large general paediatric clinic in Boston, ${ }^{1}$ but little is known about longterm outcome in young children. Estimates of constipation have varied from $0.3 \%$ of the paediatric population to as high as $8 \%$. In a study by Issenmann et al, ${ }^{2} 16 \%$ of parents of 22 month old children reported constipation in their toddlers. Constipation is usually defined in terms of changes in the frequency, size, consistency, or ease of passage of stool. Stool frequency depends on age in children. A number of studies show a decline in stool frequency from more than four stools per day during the first week of life to $1 \cdot 2$ per day at four years of age with a corresponding increase in stool size. ${ }^{3-6}$ Weaver and Steiner ${ }^{6}$ found that $85 \%$ of 1 to 4 year old children passed stools once or twice a day, and $96 \%$ did so three times daily to once every other day. Fontana $e t a l^{7}$ showed that in the first three years of life $97 \%$ of healthy children had at least one bowel movement every other day and after the third year, $95 \%$ of the children had this pattern. Constipation in young children can be defined by a stool frequency of $<3$ per week, but passage of painful bowel movements and stool retention are symptoms of constipation even when the stool frequency is $\geq 3$ per week.

Difficulties with defecation are common in infants and children. Most often the problem is short lived and of little consequence, but chronic constipation most often follows an inadequately managed acute problem. ${ }^{8}$ Constipation develops gradually in some children as a result of a progressive decrease in the frequency of bowel movements and a progressive increase in the difficulties in passing an excessively firm stool. In others, an acute episode of constipation may follow a change in diet or environment, a febrile illness, a period of dehydration, or bed rest. Little is known about the pathogenesis of constipation in childhood. Several factors most likely contribute to the development of chronic constipation such as intrinsic slow colonic motility and stool withholding secondary to painful large bowel movements.

Symptoms of constipation are often different in very young children than in older children and adults, and data on longterm treatment outcome in young children are lacking. Therefore, the aims of this report are (a) to describe the patient characteristics and the characteristic behaviour with respect to passing bowel movements of constipated infants, toddlers, and preschool children, (b) to describe our treatment programme, and (c) to report on the longterm outcome in these children.

\section{Methods}

STUDY POPULATION

Two hundred and eighty five children, 1 month to 4 years of age, were evaluated between 1980 and 1989 by the investigator for difficulties in defecation because of underlying constipation, which is not due to Hirschsprung's disease, anal atresia, or spinal disease. These children were evaluated in the Encopresis Clinic, a clinical service that provides education and management of children of all ages with defecation problems. For this report we excluded patients who had disease states that placed limitations on the act of defecation such as hypotonia, cerebral palsy, and 
severe mental retardation and patients who were less than 6 years at the time of follow up, because our intent was to evaluate outcome in school age children. This report is about 174 children $\leq 4$ years of age with idiopathic chronic constipation who were 6 years and older and had entered school at the time of follow up in May 1991. These 174 children were evaluated initially by the investigator for infrequent bowel movements, painful bowel movements (often with screaming and severe stool withholding manoeuvres), or stool soiling. The study was approved by the Institutional Human Research Review Committee in April 1991.

All patients were evaluated by the investigator. Histories were obtained and a complete physical examination was performed including an anal and rectal examination in the left lateral position. All children were considered to be constipated because they had either $<3$ bowel movements per week or painful bowel movements, or a rectal impaction, or an abdominal faecal mass on physical examination, or all four. Painful bowel movements were thought to be present if the child complained of pain during defecation or when the child exhibited screaming or crying in anticipation of, or during, defecation, if the parent reported blood on the stool or if the child had an anal fissure present at the time of examination. Stool withholding was thought to be present if the child exhibited a certain behaviour at the time of defecation, often termed 'the duty dance'. Infants tended to extend the body and contract the anal and gluteal muscles. Toddlers often rose on their toes, held their legs stiffly, and rocked back and forth holding on to a piece of furniture or onto the parent. Some children retired to a corner or another room to hide while standing stiffly or squatting.

\section{TREATMENT}

Our treatment of chronic constipation consisted of education, faecal disimpaction, prevention of future impaction, and promotion of regular bowel habits, and finally toilet training of the preschool child. Our treatment protocol was similar to the treatment approaches by Davidson et $a l^{9}$ and Levine and Bakow, ${ }^{10}$ and others, ${ }^{11-16}$ except we used a different laxative. We educated all parents and preschool children that the defecation problem is caused by the underlying chronic constipation and they were not to blame. Parents needed to be reassured that, although it is a significant chronic problem, it is not life threatening. They were told that the underlying constipation cannot be treated in a short period of time. We used a drawing of a normal colon and a distended colon to help them understand the problem. Understanding the disorder and a detailed treatment plan usually eliminated the parents' frustration, improved compliance, and allowed them to adjust and modify the treatment to provide for regular elimination."

Initial disimpaction was accomplished in the clinic. A hypertonic phosphate enema was used, with $60 \mathrm{ml} / 5 \mathrm{~kg}$ body weight in very young infants and an adult sized enema $(133 \mathrm{ml})$ for children over $10 \mathrm{~kg}$. In most children, one to two enemas resulted in good bowel clean out. Daily defecation was maintained by daily administration of laxatives beginning on the evening of the clinic visit. Milk of magnesia, an osmotic laxative, was used according to age, body weight, and severity of the constipation. In severe constipation with rock hard stools, the starting dose of milk of magnesia was approximately $2 \mathrm{ml} / \mathrm{kg}$ body weight per day. In children who had faecal retention of mostly soft formed stools, usually $1 \mathrm{ml}$ milk of magnesia/kg body weight daily was adequate. The starting dose was adjusted to induce one to two bowel movements per day, loose enough to ensure complete daily emptying of the lower bowel and prevent pain or stool soiling, or both. We did not recommend fibre supplements or purified fibre to our young children. They are not suitable for young children. We recommended fibre found naturally in many foods to parents of infants $<1$ year of age, such as in pureed fruits, vegetables, and infant cereal. The parents of toddlers and preschool children were encouraged to give several servings daily from a variety of fibre rich foods such as whole grain breads and cereals, fruits and vegetables, and legumes. Initial toilet training attempts in a toddler or preschool child who resisted toilet sitting was discouraged. The child was put back into nappies. A normal bowel pattern was accomplished first then toilet training was restarted. Rewards for toilet sitting and later for bowel movements into the toilet were given. The child was encouraged to sit on the toilet for up to five minutes, three to four times a day, after meals.

Many patients returned until the constipation had resolved, others continued treatment after two visits with their local physician. At least one more visit to the Encopresis Clinic was accomplished with all patients after the initial evaluation to review the stool records, assess progress, and repeat the abdominal and rectal examination and to discuss the treatment plan. This was done to be sure that the constipation was and would be adequately treated. Dose adjustment was made if necessary. The laxative dose was gradually decreased after two to three months to a dose that maintained one bowel movement daily. About $50 \%$ of infants and toddlers were able to discontinue the laxative after three to four months.

\section{FOLLOW UP QUESTIONNAIRE}

The follow up questionnaire was sent to the parents of the 174 children with idiopathic chronic constipation who were of school age. This questionnaire included questions on the present history of abdominal pain, stool withholding, constipation, frequency and consistency of bowel movements, size of the bowel movements, and if the bowel movements occasionally clogged the toilet. It included questions on the presence and frequency of stool soiling, and treatment being given such as stool softeners, laxatives, suppositories, enemas, or others, and their dose and frequency of use and if day wetting or night wetting was present at the time of follow up. It contained questions on the grade in school, current school performance, and if the child was in a special class, to verify normal development. Ninety parents and patients $(52 \%)$ 
TABLE I Patient characteristics at time of initial evaluation $(n=174)$

\begin{tabular}{|c|c|c|c|c|c|}
\hline Age at initial evaluation (y) & $\begin{array}{l}0 \cdot 1-4 \\
n=174\end{array}$ & $\begin{array}{l}0 \cdot 1-1 \\
n=43\end{array}$ & $\begin{array}{l}>1-2 \\
n=29\end{array}$ & $\begin{array}{l}>2-3 \\
n=47\end{array}$ & $\begin{array}{l}>3-4 \\
n=55\end{array}$ \\
\hline $\begin{array}{l}\text { Boys:girls } \\
\text { Before unsuccessful treatment } \\
\text { Stool frequency/week } \\
\text { Stools defecated into toilet/week } \\
\text { Painful bowel movements } \\
\text { Stool withholding } \\
\text { History of urinary tract infection } \\
\text { Palpable abdominal mass } \\
\text { Abdominal or huge rectal stool mass }\end{array}$ & $\begin{array}{l}87: 87 \\
86 \% \\
4(5) \\
4(5) 57 \star \\
67 \% \\
97 \% \\
9 \% \\
42 \% \ddagger \\
77 \%\end{array}$ & $\begin{array}{l}23: 20 \\
71 \% \\
5(5) \\
- \\
60 \% \\
89 \% \\
7 \% \\
19 \% \\
70 \%\end{array}$ & $\begin{array}{l}11: 18 \\
86 \% \\
5(4) \\
6(9) 6^{\star} \\
86 \% \\
95 \% \\
7 \% \\
28 \% \\
59 \%\end{array}$ & $\begin{array}{l}19: 28 \\
97 \% \\
4(5) \\
2(2) 18^{\star} \\
64 \% \\
100 \% \\
9 \% \\
51 \% \\
87 \%\end{array}$ & $\begin{array}{l}34: 31 \\
87 \% \\
4(5) \\
4(5) 33^{\star} \\
65 \% \\
100 \% \\
13 \% \\
60 \% \\
84 \%\end{array}$ \\
\hline
\end{tabular}

Values are mean $(\mathrm{SD})$; ${ }^{\star}$ no of patients; $\nmid \mathrm{p}<0.001 ;$ cross categorisation using Pearson's $\chi^{2}$ test showed that the frequency of severe constipation increased with the duration of constipation.

returned the follow up questionnaire or completed the questionnaire by telephone. Information on 84 children could not be retrieved for follow up. The parents of the 33 children who had not recovered were interviewed a second time to answer the question whether the constipation/soiling problems had persisted or recurred, because we were not able to determine this from the initial questionnaire.

\section{STATISTICAL ANALYSIS}

Statistical methods included the Wilcoxon nonpaired rank sum test and Fisher's exact probability test, analysis of variance, and Pearson's $\chi^{2}$ test with significance accepted at $5 \%$ value. Results were expressed as mean (SD).

\section{Results}

Table I shows the age distribution and patient characteristics at the initial evaluation of the 174 children with idiopathic constipation. There were 87 boys and 87 girls in the study. Their mean age at the time of evaluation was $2 \cdot 2(1 \cdot 3)$ years with an age range of one month to four years. The mean age at onset of symptoms of constipation was 11 (13) months. Stool frequency was difficult to assess. It could be elicited in 168 children and was 4 (5) bowel movements per week. The difficulty arose in that some of the children had several stools per day, but apparently evacuated incompletely, as shown by periodic passage of very large amounts of stool or the presence of a faecal impaction. Stool frequency was $<1$ per week in $13 \%$ of children, $\leq 1$ per week in $32 \%$, and $<3$ per week in $58 \%$. The parents described stool withholding behaviours in $97 \%$ of the children but often misinterpreted this behaviour as extreme efforts to pass stool.

TABLE II Patient characteristics at time of initial evaluation and outcome $(n=90)$

\begin{tabular}{|c|c|c|c|c|c|}
\hline Age at initial evaluation (y) & $\begin{array}{l}0 \cdot 1-4 \\
n=90\end{array}$ & $\begin{array}{l}0 \cdot 1-1 \\
n=12\end{array}$ & $\begin{array}{l}>1-2 \\
n=16\end{array}$ & $\begin{array}{l}>2-3 \\
n=25\end{array}$ & $\begin{array}{l}>3-4 \\
n=37\end{array}$ \\
\hline $\begin{array}{l}\text { Boys:girls } \\
\text { Follow up }\end{array}$ & $50: 40$ & $9: 3$ & $7: 9$ & $11: 14$ & $23: 14$ \\
\hline $\begin{array}{l}\text { Years after initial evaluation } \\
\text { Range }(y) \\
\text { Age }(y)\end{array}$ & $\begin{array}{l}6 \cdot 9(2 \cdot 7) \\
3-12 \\
9 \cdot 6(2 \cdot 8)\end{array}$ & $\begin{array}{l}6 \cdot 9(2 \cdot 5) \\
5-12 \\
7 \cdot 2(2 \cdot 5)\end{array}$ & $\begin{array}{l}7 \cdot 3(2 \cdot 7) \\
4-12 \\
9 \cdot 0(2 \cdot 6)\end{array}$ & $\begin{array}{l}7 \cdot 0(3 \cdot 0) \\
3-12 \\
8 \cdot 9(3 \cdot 0)\end{array}$ & $\begin{array}{l}6 \cdot 4(2 \cdot 7) \\
3-12 \\
9 \cdot 9(2 \cdot 7)\end{array}$ \\
\hline $\begin{array}{l}\text { Outcome } \\
\text { Recovered }{ }^{\star} \\
\text { Not recovered } \\
\text { Not soiling, but constipated or on }\end{array}$ & $\begin{array}{l}63 \% \\
37 \%\end{array}$ & $\begin{array}{r}92 \% \\
8 \%\end{array}$ & $\begin{array}{l}81 \% \\
19 \%\end{array}$ & $\begin{array}{l}40 \% \\
60 \%\end{array}$ & $\begin{array}{l}62 \% \\
38 \%\end{array}$ \\
\hline $\begin{array}{l}\text { laxatives } \\
\text { Soiling }\end{array}$ & $\begin{array}{l}19 \% \\
18 \%\end{array}$ & $\begin{array}{l}8 \% \\
0 \%\end{array}$ & $\begin{array}{r}13 \% \\
6 \%\end{array}$ & $\begin{array}{l}32 \% \\
28 \%\end{array}$ & $\begin{array}{l}16 \% \\
22 \%\end{array}$ \\
\hline
\end{tabular}

Values are mean (SD); * recovered was defined as no soiling with $\geq 3$ bowel movements/week while not receiving treatment.
Nine per cent of patients had at least one urinary tract infection.

The physical examination provided information on the constipation. A large abdominal faecal mass was palpated in $42 \%$ of patients, indicating a severe form of constipation. The mass rarely extended throughout the entire colon. Commonly the faecal mass was felt suprapubically and midline. The percentage of children with an abdominal faecal mass present at initial evaluation increased significantly from $19 \%$ in children $\leq 1$ year of age, to $28 \%$ in children $>1$ to 2 years of age, to $51 \%$ in those $>2$ to 3 years of age, and to $60 \%$ in those $>3$ to 4 years of age $\left(p<0.001\right.$; Pearson's $\chi^{2}$ test), suggesting that the severity of constipation increased with the duration of constipation (see Table I). Inspection of the anal canal showed protruding faecal material in only a few patients. The rectum was packed with stool in $64 \%$ of patients, either of hard consistency, or more commonly the outside of the faecal impaction felt like clay and the core of the impaction was hard. No rectal stool mass was felt in $36 \%$ of children, $13 \%$ being already started on laxatives and others having had a recent bowel movement. A palpable abdominal faecal mass or a large amount of stool in the rectal ampulla was felt in $77 \%$ of patients. Painful bowel movements assessed by reports of pain complaints, screaming and sweating, presence of an anal fissure or blood on stool were reported in $\mathbf{7 7 \%}$ of patients. Stool soiling was difficult to assess, many children were not at an age to be toilet trained. No soiling was present in 12 of 55 children $(22 \%)>3$ to 4 years of age.

The age at attempted follow up was 9.9 (2.8) years with a range of 6 to 16 years, this was 6.9 $(2 \cdot 7)$ years with a range of 3 to 12 years after the initial evaluation. Follow up by questionnaire was accomplished in $52 \%$ of eligible patients; in $28 \%$ of those $\leq 1$ year of age, $55 \%$ of those $>1$ to 2 years of age, $53 \%$ of those $>2$ to 3 years of age, and $67 \%$ of those $>3$ to 4 years of age. To evaluate the possibility of bias in the group with follow up, the data from the initial history and physical examination of the 90 children in whom we obtained a follow up were compared with those from the 84 children with no follow up. There was a significant difference in age at initial evaluation, with the children with follow up being significantly older $(2.5(1.5)$ years $)$ than those without follow-up $(1 \cdot 8 \quad(1 \cdot 3)$ years; $\mathrm{p}<0.01)$. There were no other significant differences between these two groups $(p>0 \cdot 1)$.

Tables II, III, and IV give the outcome results. Fifty seven children (63\%) had recovered, defined as no soiling with $\geq 3$ bowel movements per week and receiving no drugs or treatment. The recovery rate in children $\leq 2$ years was significantly higher than in children $>2$ to 4 years of age $(p<0 \cdot 005)$. Only $28 \%$ of children $\leq 1$ year of age could be re-evaluated, and therefore, the $92 \%$ recovery rate in this age group needs to be viewed with caution. The frequency of bowel movements in the recovered children ranged from 3 to 14 per week, mean $5 \cdot 8$ $(2 \cdot 4)$. As can be seen in Table II, 33 children (37\%) were still constipated, on laxatives or soiling. Seventeen (19\%) had no soiling, eight were still constipated with $<3$ bowel movements 
TABLE III Patient characteristics at time of initial evaluation by outcome $(n=90)$

\begin{tabular}{llll}
\hline & & \multicolumn{2}{l}{ Not recovered } \\
\cline { 3 - 4 } & & $\begin{array}{l}\text { Constipated or receiving } \\
\text { laxatives, no soiling } \\
n=17\end{array}$ & $\begin{array}{l}\text { Soiling } \\
n=16\end{array}$ \\
\hline Becovered & $n=57$ & $6: 11$ & $11: 5$ \\
Age (y) & $33: 24$ & $2 \cdot 8(0 \cdot 9)$ & $2 \cdot 9(0 \cdot 7)$ \\
Onset of constipation (month) & $2 \cdot 4(1 \cdot 3)$ & $14(13)$ & $14(12)$ \\
Before unsuccessful treatment & $89 \%$ & $85 \%$ & $77 \%$ \\
Stool frequency/week & $5 \cdot 0(5 \cdot 6) 56 \dagger$ & $2 \cdot 8(2 \cdot 3) 17 \dagger$ & $6 \cdot 1(8 \cdot 3) 16 \dagger$ \\
Stool defecated into toilet/week & $3 \cdot 1(5 \cdot 3) 22 \dagger$ & $5 \cdot 0(6 \cdot 5) 6 \dagger$ & $4 \cdot 8(6 \cdot 6) 9 \dagger$ \\
Painful bowel movements & $77 \%$ & $53 \%$ & $38 \% \ddagger$ \\
Stool withholding & $97 \%$ & $100 \%$ & $89 \%$ \\
History of urinary tract infection & $7 \%$ & $24 \%$ & $6 \%$ \\
Palpable abdominal mass & $37 \%$ & $53 \%$ & $44 \%$ \\
Abdominal or huge rectal stool mass & $74 \%$ & $82 \%$ & $75 \%$ \\
\hline
\end{tabular}

Values are given as mean (SD); ${ }^{\star}$ recovered was defined as no soiling with $\geq 3$ bowel movements/week and not receiving treatment; tno of patients; $\neq p<0.005$ from recovered patients.

per week, and 11 were receiving treatment (laxatives, stimulants, suppositories or occasional enemas) to prevent constipation. Two of these 17 children were constipated despite the use of laxative. Sixteen children (18\%) had faecal soiling with soiling frequency ranging from once a week to daily, mean 3 (2) soilings per week, despite some treatment in four patients. Constipation or faecal soiling, or both recurred and persisted until follow up as soon as the laxatives were stopped in 31 of 33 children who did not recover. Only in two patients did problems with constipation recur after they had been successfully treated.

Table III gives the patient characteristics of children who recovered and those who did not as noted in the initial history and physical examination. As can be seen in Table III, children who recovered were similar to both groups of the children who did not in sex distribution, age at initial evaluation and onset of constipation, stool frequency, percentage of patients with stool withholding, history of urinary tract infection, and stool retention. Painful bowel movements during the initial evaluation were reported significantly more often in children who recovered than in the soiling group $(\mathrm{p}<0.005)$. Table IV shows that children who recovered were similar to both groups of children who did not in age at follow up, years of follow up, and frequency of day or night wetting. A few recovered children occasionally clogged the toilet with their stools (4\%), had abdominal pain

TABLE IV Patient characteristics at time of the follow up questionnaire $(n=90)$

\begin{tabular}{|c|c|c|c|}
\hline & \multirow[b]{2}{*}{$\begin{array}{l}\text { Recovered } \\
n=57\end{array}$} & \multicolumn{2}{|l|}{ Not recovered } \\
\hline & & $\begin{array}{l}\text { Constipated or receiving } \\
\text { laxatives, no soiling } \\
n=17\end{array}$ & $\begin{array}{l}\text { Soiling } \\
n=16\end{array}$ \\
\hline $\begin{array}{l}\text { Years after initial evaluation } \\
\text { Age }(y) \\
\text { Constipation by stool frequency }(<3 /\end{array}$ & $\begin{array}{l}6 \cdot 9(2 \cdot 7) \\
9 \cdot 4(2 \cdot 7)\end{array}$ & $\begin{array}{l}6 \cdot 8(2 \cdot 4) \\
9 \cdot 7(2 \cdot 8)\end{array}$ & $\begin{array}{r}6 \cdot 9(3 \cdot 3) \\
10 \cdot 0(3 \cdot 0)\end{array}$ \\
\hline week & $0 \%$ & $47 \% \dagger$ & $31 \% \dagger$ \\
\hline Stools defecated into toilet/week & $5 \cdot 8(2 \cdot 4)$ & $2 \cdot 8(1 \cdot 0) \dagger$ & $3 \cdot 9(2 \cdot 3) \dagger$ \\
\hline Very large to large stool diameter & $24 \%$ & $65 \% \dagger$ & $81 \% \dagger$ \\
\hline Very hard stool consistency & $2 \%$ & $24 \% \dagger$ & $25 \% \dagger$ \\
\hline Stool clogs the toilet & $4 \%$ & $47 \% \dagger$ & $44 \% \dagger$ \\
\hline Abdominal pain & $9 \%$ & $35 \% \dagger$ & $18 \%$ \\
\hline Stool withholding & $5 \%$ & $29 \% \dagger$ & $63 \% \dagger$ \\
\hline Soiling episodes/week & $0 \%$ & $0 \%$ & $2 \cdot 8(2 \cdot 3)$ \\
\hline Laxative treatments & $0 \%$ & $65 \%$ & $25 \%$ \\
\hline Day wetting & $0 \%$ & $0 \%$ & $6 \%$ \\
\hline Bed wetting & $4 \%$ & $6 \%$ & $19 \%$ \\
\hline
\end{tabular}

Values are given as mean (SD); ${ }^{*}$ recovered was defined as no soiling with $\geq 3$ bowel movements/week and not receiving treatment; $\nmid \mathrm{p}<0.02$ from recovered patients.
(9\%), and still exhibited stool withholding (5\%). Stools with very large diameters, very hard stools, and stools that clogged the toilet were reported significantly more commonly in both groups of children who did not recover than in the recovered group $(p<0.02)$. There was no correlation between the number of visits to our Encopresis Clinic and treatment outcome $(\mathrm{p}>0 \cdot 1)$.

As expected, the data from the 33 children who did not recover when compared with the data from the 57 recovered children showed significantly higher incidence rates of symptoms of constipation at follow up; very large diameter stools, very hard stool consistency, stools that clogged the toilet, stool withholding $(p<0.001)$, abdominal pain $(\mathrm{p}<0.04)$, and a significant decrease in the number of bowel movements per week $(\mathrm{p}<0.001)$.

\section{Discussion}

A group of 174 infants, toddlers, and preschool children is presented who showed evidence of constipation early in life. Painful bowel movements were present in $67 \%$, stool withholding in $97 \%$, and a rectal/abdominal stool mass in $77 \%$. Similar findings were made by Partin $e t \mathrm{al}^{13}$ who reported that $86 \%$ of their 74 patients $<3$ years of age presented with pain, $97 \%$ had stool withholding, and $71 \%$ were impacted.

Patients were disimpacted and then treated with dietary fibre and daily milk of magnesia, and the laxative was slowly discontinued once normal bowel movements had been accomplished. Longterm outcome could be evaluated in 90 patients. Fifty seven children (63\%) had recovered, defined as no soiling with $\geq 3$ bowel movements per week and not receiving treatment. By our definition these children had recovered, but their parents still reported that $5 \%$ of recovered children had stool withholding, $9 \%$ had abdominal pain, and $24 \%$ occasionally passed large stools. Thirty three children (37\%) had not recovered. In 31 of these 33 children the constipation returned as soon as the laxative was discontinued. Abdominal pain was still present in $27 \%$, stool withholding in $45 \%$, constipation with $<3$ bowel movements per week in $39 \%$, bowel mvoements that clogged the toilet in $45 \%$, laxative use in $33 \%$, and soiling in $48 \%$ of the children who did not recover.

In a study by Issenmann et $a l,{ }^{2} 16 \%$ of parents of 22 month old children reported constipation in their toddlers. We can only speculate why such a large number of young children experiences chronic constipation. It is probably because an episode of acute constipation had not received adequate treatment. Attention must be paid not only to stool frequency ${ }^{3-6}$ and stool consistency, but to painful bowel movements, the degree of straining, and the time it takes to evacuate stools in young children. Many of our patients had unsuccessful interventions for months before our evaluation. Most often the intervention did not change stool frequency or stool consistency, or both. Some children had received a laxative, and when given, it was either given in minimal dose or given for too short a time. The laxative dose required to treat consti- 
pation in the young child is much higher than the suggested doses on the label. In addition, the warning on the label may lead to doubts about the safety of its use in young children. Sometimes parents had stopped the laxative because the stool withholding manoeuvres or screaming did not stop as soon as loose stools were induced. The actual choice of drug is not as important as an adequate dose and the child's and parents' compliance with the treatment regimen. Suggested doses of commonly used laxatives are given in reference 17.

Our outcome data cannot be compared with the existing published works because previous reports on chronic constipation with and without faecal soiling often combined younger and older children $^{914-16}$ or children with idiopathic constipation and anorectal disorders, or both. ${ }^{14}$ Therefore, no outcome data for a similar young patient group can be found. In addition, our study is the first to present longterm follow up data in a large number of constipated children $\leq 4$ years of age.

Similar to Fitzgerald, ${ }^{8}$ I had re-treated a few patients months to years after their initial management, but one third of patients still had symptoms of constipation $6.8(2.8)$ years after initial evaluation. None of the children who did not recover were receiving medical care for symptoms of constipation at the time of follow up.

Poor patients/parent compliance has been blamed for less than ideal results in major series on constipation in children..$^{10}$ Ideally, all patients should have had the same number of follow up visits. Unfortunately, some of the patients could not return for frequent follow up visits to our clinic because of distance and also health care costs and were therefore referred back with our treatment plan to their own physicians. We cannot completely rule out that treatment outcome would have been better if all patients had received continued care and reinforcement by the investigator, but our study showed that there was no correlation between the number of visits to the Encopresis Clinic and treatment outcome $(p>0 \cdot 1)$.

Our study showed that constipated children $<2$ years of age responded better to treatment than children $>2$ years of age, supporting the conclusion by Clayden ${ }^{18}$ that treatment should be given early to prevent development of severe constipation or faecal soiling, or both.
In our young constipated children, the ratio of boys to girls was $1: 1$, while the ratio in our patients $\geq 5$ years of age was $3-4: 1,{ }^{19}$ and in other centres $6: 1 .^{\prime}$ We evaluated as many young boys as young girls for constipation, but twice as many boys than girls had soiling at follow up, while 1.8 times more girls than boys were still constipated or receiving laxatives for constipation at follow up.

We found that chronic constipation in young children can persist for many years. Our study showed that $37 \%$ of them were still constipated, receiving laxatives, or soiling 3 to 12 years after start of treatment, or all three. Children who have not recovered deserve continued follow up, to reinforce and adjust treatment and to prevent faecal soiling.

Published as an abstract in the American Fournal of Diseases in Childhood 1992; 1946: 465A.

1 Levine MD. Children with encopresis: a descriptive analysis. Pediatrics 1975; 56: 412-6.

2 Issenman RM, Hewson S, Pirhonen D, Taylor W. Are chronic digestive complaints the result of abnormal dietary patterns? An F Dis Child 1987; 141: 679-82.

3 Nyhan WL. Stool frequency of normal infants in the first week of life. Pediatrics 1952;10: 414-25.

4 Lemoh JN, Brooke OG. Frequency and weight of normal stools in infancy. Arch Dis Child 1979; 54: 719-20.

5 Wolman IJ. Laboratory applications in clinical pediatrics. New York: McGraw Hill, 1957: 696-7.

6 Weaver LT, Steiner H. The bowel habit of young children. Arch Dis Child 1984; 59: 649-52.

7 Fontana M, Bianchi C, Cataldo F, Conti Nibali S, Cucchiara S, Gobio Casali L, et al. Bowel frequency in healthy children. Acta Paediatr Scand 1989; 78: 682-4.

8 Fitzgerald JF. Constipation in children. Pediatr Rev 1987; 8: 299-302

9 Davidson $\mathrm{M}$, Kugler MM, Bauer $\mathrm{CH}$. Diagnosis and management in children with severe and protracted constipation and obstipation. F Pediatr 1963; 62: 261-75.

10 Levine MD, Bakow H. Children with encopresis: a study of treatment outcome. Pediatrics 1976; 58: 845-52.

11 Lewis AV, Hillemeier AC. Pediatric constipation: diagnosis and treatment. Practical Gastroenterology 1989; 13: 31-9, 67 12 Clayden G. Chronic constipation in childhood. Postgraduate Update 1989; June: 1243-55.

13 Partin JC, Hamill SK, Fischel JE, Partin JS. Painful defecation and fecal soiling in children. Pediatrics 1992; 89: tion and

14 Sarahan T, Weintraub WH, Coran AG, Wesley JR. The successful management of chronic constipation in infants and children. F Ped Surg 1982;17: 171-4.

15 Abrahamian FP, Lloyd-Still JD. Chronic constipation in childhood: a longitudinal study of 186 patients. $\mathcal{F}$ Pediatr childhood: a longitudinal study

16 Clayden GS. Management of chronic constipation. Arch Dis Child 1992; 67: 340-4.

17 Loening-Baucke V. Elimination disorders. In: Greydanus DE, Wolraich ML, eds. Behavioral pediatrics. New York: Springer Verlag, 1991: 280-97.

18 Clayden GS. Constipation in childhood: treatment should be given early. $B M \mathcal{F}$ 1989; 299: 1116-7.

19 Lening-Baucke V. Factors determining outcome in children with chronic constipation and faecal soiling. Gut 1989; 30: 999-1006. 